\title{
The end of the antibiotic era
}

\author{
Guillermo Francisco Rosales Magallanes* \\ Infectious diseases paediatrician, Hospital ISSSTECALI Mexicali, Baja California, Mexico
}

In the most recent years, we are being faced with something described in modern medical literature at the start of the century: drug resistant bacteria. In reserve to so many prognosis we are currently taking decisions against the clock in our hospitals, making use of all resources to maintain health amongst our patients. It would seem that as we face more challenges to do this, the amount of drug resistant bacteria increases. The current conduct of the primary care clinician when dealing with patients is still that of empiric treatment, there is no knowledge of the local microorganisms circulating in their care unit, nor the most common causing pathogen of such infections and as such there is still an overuse of one of our most priced resources: antibiotics. To current clinicians, an "empiric therapy" still gives them peace of mind though it is actually increasing our resistances, and as such making us spend more and more of this precious resource. Though things make look grim, there is still some hope in this clinical chaos, a hope for improvement. The control of antibiotics must be crucial in all zones in a hospital setting, not only in the treatment of a patient in the critical care unit. It is of utmost importance to learn the local microbiota in hospital since it not only allows us to reduce the overuse of antibiotics, it has been proven to reduce the hospital stay, and improve the prognosis of patients with in turn increases their quality of life and reduces hospital costs; the employment of protocols established by hospital acquired infections group causes all of these things. It is incredible for clinicians to still lack culture in hand washing, that there are still some who begrudge the most economic and simple procedure we have to reduce infection rates and limit their spread. We have looked for strategies to make this tool more effective yet it would seem it is given no priority in hospitals, instead hospitals look for better diagnostic and therapeutic technology, how can we use all of this new technology when we can't even employ the most rudimentary of public health practices? Doctors and nurses in charge of the control of infections are set off as being "obsessive" or "ungrateful" in the other services, when their conduct should be able to focus on the professional maturity that we must abide by. We owe it to our profession, and to our patients to look for the way to work amongst our fellow specialists, sub specialists and other medical personal, to help and support the campaigns designed to conserve and improve our patients' standard of living. We must improve our personal conduct, not opting of egocentrism, but to accept each part of the medical personnel as a part of the machine which we all work to move, and to learn that if one of the pieces fail, the whole machine falls apart. This is not about searching for new antibiotics, it is about looking to improve our actions as health professionals. The end of the antibiotic era is approaching and there is still much to do.
Copyright: (C2018 Magallanes GFR. This is an open-access article distributed under the terms of the Creative Commons Attribution License, which permits unrestricted use, distribution, and reproduction in any medium, provided the original author and source are credited.
Correspondence to: Guillermo Francisco Rosales Magallanes, Infectious diseases paediatrician, Hospital ISSSTECALI Mexicali, Baja California, Mexico, E-mail: dr_gmagal76@hotmail.com

Received: March 20, 2018; Accepted: April 04, 2018; Published: April 06, 2018 